\title{
Dimensional Analysis under Linguistic Pythagorean Fuzzy Set
}

\author{
Aldo Joel Villa Silva ${ }^{1, *(\mathbb{D})}$, Luis Pérez-Domínguez ${ }^{1}$ (D) Erwin Martínez Gómez $^{1}{ }^{\mathbb{D}}$, David Luviano-Cruz ${ }^{1}$ (D) \\ and Delia Valles-Rosales ${ }^{2}$ \\ 1 Department Ingeniería Industrial y Manufactura, Universidad Autónoma de Ciudad Juárez, \\ 32315 Ciudad Juárez, Mexico; luis.dominguez@uacj.mx (L.P.-D.); emartine@uacj.mx (E.M.G.); \\ david.luviano@uacj.mx (D.L.-C.) \\ 2 Department of Industrial Engineering, New Mexico State University, Las Cruces, NM 88003, USA; \\ dvalles@nmsu.edu \\ * Correspondence: ing.aldojvillasilva@gmail.com
}

Citation: Villa Silva, A.J.;

Pérez-Domínguez, L.; Martínez

Gómez, E.; Luviano-Cruz, D.;

Valles-Rosales, D. Dimensional Analysis under Linguistic

Pythagorean Fuzzy Set. Symmetry

2021, 13, 440. https://doi.org/

$10.3390 /$ sym 13030440

Academic Editor: Sergei D. Odintsov

Received: 19 January 2021

Accepted: 3 March 2021

Published: 8 March 2021

Publisher's Note: MDPI stays neutral with regard to jurisdictional claims in published maps and institutional affiliations.

Copyright: (C) 2021 by the authors. Licensee MDPI, Basel, Switzerland. This article is an open access article distributed under the terms and conditions of the Creative Commons Attribution (CC BY) license (https:/ / creativecommons.org/licenses/by/ $4.0 /)$.

\begin{abstract}
Dimensional analysis under linguistic Pythagorean fuzzy set (DA-LPFS) is a technique to handle qualitative (intangible) as well as the interactions between criteria, by combining dimensional analysis (DA) and Pythagorean fuzzy set (PFS) with linguistic variables. In this paper, a novel DA method is proposed for LPFSs based in a PFS extension, in order to consider the mutual relationship among criteria and handle qualitative (fuzzy) and quantitative (crisp) information usually involved in Multi-criteria decision making (MCDM) problems. Finally, DA-LPFS is applied to handle a case concerning the selection of $\mathrm{CNC}$ router to illustrate the applicability of the method.
\end{abstract}

Keywords: multicriteria decision making; dimensional analysis; linguistic pythagorean fuzzy set; supplier's selection

\section{Introduction}

Dimensional analysis (DA) is a tool used for design, classification, performance, and analysis or synthesis of resulting data [1] and is mainly based on the Buckingham theorem [2] as a mathematical technique that combines diverse heterogeneous attributes into one dimensionless index. DA assumes that there is a best solution better than the rest of the solutions, and operates a comparison alternative in evaluation against the best solution to generate an index of similarity, therefore the highest index of similarity is selected as the best alternative to the multicriteria decision making (MCDM) problem [3].

Actually, DA is used in physics and engineering, but it has also been applied in other disciplines, such as biometry, physiology, economics, astronomy, and even social sciences [4]. In 1951, Huntley [5] demonstrated that DA can be used as an anatical tool in selecting experiments, obtaining solutions in complex problems. Furthermore, in 1966 Naddor [6] demonstrated that DA could simplify solutions in queueing theory, inventory, and linear programming. In addition, applying DA has been published including warehouse layout, logistics networks, supplier performance, and selection of industrial robots [7]. In 1993, Willis [8] proposed an adapted version of DA in order to manage MCDM problems such as supplier selection problems and Humphreys in 1998 also applied DA to handle the suppliers in the selection process [9]. Furthermore, Li and Fun [10] developed a VPI (vendor performance index) using DA and a supplier performance measure.

DA similarly with other traditional methods requires a decision matrix, an ideal solution, and criteria weights to be established. However, DA is recommended for the assessment of alternatives as it has several advantages: (1) it is independent in the management of different attributes, (2) it is robust as it is less sensitive in the intangible characteristics of the MCDM [11]. In addition, one of the strongest properties of DA is its ability to integrate the opinions given by a cluster of DM concerning about alternatives, criteria interrelationship and its importance [3]. For example, in the supplier selection problem it is commonly found that criteria may conflict with other. For instance, in the 
case of quality against price, the most expensive is a good product, or service and quality will be better, however, a DM will search for the cheaper and better quality [12].

Most evaluation models ignore the interrelationships between criteria or do not employ methods that examine deeply the interrelationships. They usually assume that criteria are independent, however, they are not always independent of each other [12-15]. At the same time the values of criteria are generally assessed by experts according to Qin [16]. It is often difficult to ensure the absolute objectivity as the MCDM process in real life usually involves vague or imprecise information and the independence of criteria is not mandatory [15].

Despite the advantages of DA, it only can handle crisp (non-fuzzy) numbers [3]. However, most of traditional MCDM approaches use quantitative values [17].

In this context, one of the best resources to solve this issue is by applying fuzzy set theory due to its use to compensate for the subjectivity in human judgment $[18,19]$. Fuzzy sets (FS) theory was first conceptualized in 1965 by Zadeh [20]. This theory is known due to its flexibility when handling imprecision and uncertainty in human decisions [13]; this is because it represents vague information and relates to an imprecise evaluation. Since 1970, numerous fuzzy models have been proposed. Later in 1986, Atanassov [21] introduced the intuitionistic fuzzy set (IFS), which is characterized by membership and nonmembership degrees and it became a more accurate tool when dealing with fuzziness and vagueness [22] Fuzziness is inherent in the sense that it has no clear-cut referential boundary, and is not resolvable with respect to context, and vague expression can be denoted by an ambiguous expression [23]

On the other hand, the Pythagorean fuzzy set (PFS) proposed by Yager [24] is also represented by values of membership and nonmembership [24], though it can be differentiated from the IFS: the sum of the degree of membership and nonmembership which the alternative satisfies certain criteria, given by experts, it can be more than the unit, but its square sum is equal to or less than the unit [25].

In recent years, computing with words $(\mathrm{CW})$ has become an interesting methodology applied in decision making [26,27]. CW is a methodology based on fuzzy logic where words represent the role of labels of perceptions [28], furthermore, it allows to model these perceptions and preferences [29], using words simulates human thought and gets closer the breach between human's brain mechanisms and the machine's processes in order to deal uncertainty $[26,29,30]$. CW involves an integration of natural languages and computation with fuzzy variables, fuzzy numbers can be represented as qualitative information, as a result of this fusion wide-ranging ramifications and applications have been developed and applied in subjective evaluations and decision making [31,32].

The most recent methods are using linguistic expressions, to map linguistic labels are used to express assessment information in the form of natural linguistics, then, a better focus may be the use of linguistic terms rather than numbers [33]. For example, when evaluating goods, we can not only use "good" or "bad" but also choose to express "very good", "good", "bad", and "very bad" rather than numbers [34]. In this context Liu and Li developed MCDM decision-making based on Pythagorean fuzzy uncertain linguistic aggregation operators [35], furthermore, there is similar research in the literature [33,35-37].

In addition Garg applied PFS [34] with the concept of linguistic term sets (LTSs) [23,38,39] and introduced the linguistic Pythagorean fuzzy set (LPFS) [34] that is able to assess qualitative information, due in real life making decisions involve vague, imprecise and uncertain situations; and many problems present qualitative aspects.

Usually the supplier selection problem involves quantitative and qualitative criteria [17], as tangible and intangible factors are essential in selecting the best supplier [40]. In the literature there are diverse methodologies that have been developed and applied to deal with the supplier selection problem in fuzzy environment in addition to linguistic labels to assess a set of factors [41].

According to literature review, there are three gaps in MCDM field that need to be addressed: 
- To assume that all the input data (criteria) are independent and do not take into consideration the mutual relationship among input data, therefore, few studies are concerned about considering the interrelationship among criteria in MDCM [12-15,42].

- To assume that limitations to represent evaluation information on how to handle qualitative (fuzzy) and quantitative (crisp) information in the context of MCDM problems $[43,44]$.

- There is no consensus among experts that is widely accepted of generalized application, which is the best methodology to treat supplier selection, as diverse MCDM methods have been applied for supplier selection, furthermore, is a MCDM problem that has not been solved [45].

The motivation of this work is to find a model that is able to take into consideration interrelationships that may exist among the criteria in the MCDMs, and at the same time handle qualitative information. In order to tackle the gaps mentioned above, in this study, we propose DA under linguistic Pythagorean fuzzy (DA-LPFS) to solve a supplier selection problem. The main novelty and contributions of this work are listed below

- DA is used to treat the interrelationship among the multi-input arguments, due to the advantages mentioned above.

- $\quad$ LPFS to overcome limitations concerning qualitative (fuzzy) criteria using linguistic assessments instead of numerical ones, in order to make DM's opinions reliable.

- $\quad$ Get a method using DA under LPFS environment to solve a supplier problem, where index similarity (IS) equation of DA is replaced by linguistic Pythagorean fuzzy equations in order to make operative the decision matrix and obtain the ranking of alternatives.

The remainder of this paper is organized as follows. In Section 2, preliminaries of supplier selection, DA, IFS, PFS, and LPFS, are given. In Section 3, the methodology of integration of DA and LPFSs is defined for dealing with both types of information, quantitative and qualitative, and a procedure is given. In Section 4, we present a case study to illustrate our technique DA-LPFS. Finally, the conclusion is given in Section 5.

\section{Preliminaries}

In this section, we briefly mention some fundamental concepts and theories of suppler selection [46,47], DA [1], IFS [21], PFS [24,25], and LPFS [34].

\subsection{Supplier Selection}

Despite the volume of research, mainly in the area of supplier selection, little attempt has been made in order to measure the impact of assessment on the buying company's business performance [46]. According to Nielsen [47] quoting Dickson [48] and Weber [49] defined 23 distinct criteria are identified in various supplier selection problems, criteria like "quality", "delivery schedule" and "warranties" "price", "production capability", "technical capability", "vendor reputation", "financial position" [50]. However, studies have explored the different supplier selection criteria and cannot calculate the relative importance for such criteria and are less effective in assessment closer to human subjectivity and preferences [50]. Therefore, criteria used in supplier assessment include quantitative and qualitative criteria [18]. Next we present some authors and the criteria of these may vary according to the environment and context that is the object of study:

According to Dickson [48]: The net price, the ability of each vendor to meet quality specifications consistently, the repair service, the ability of each vendor to meet specified delivery schedules, the geographic location, the financial position, the production facilities, the amount of past business, the technical capability, the management and organization, the future purchases, the communication system, the operational controls, the position in the industry, the labor relations record, the attitude, the desire for your business, the warranties and claims policies, packaging, training aids and educational courses, compliance with your procedures, performance history.

Swift [51] quoting: Shipley and Dempsey: price, quality, and reliable delivery. 
Lehmann and O'Shaughnessy [52]: price, quality, delivery, and service.

Ansari and Modarress [53]: quality, delivery, net price, geographical location, attitudes [54]. Spekman [54]: product, service, experience, price, and availability.

Weber et al. [49]: the product quality, on-time delivery, performance history of supplier and warranties and claimed policies

Wilson [55]: Quality, price, delivery and service.

Doney and Cannon [56]: Trust in the supplier firm and trust in the salesperson.

Verma and Pullman [57]: Quality, on-time delivery, price, and flexibility.

Kannan [46]: Cost, quality, delivery performance, capability, and culture.

Chang et al. [58]: Technology ability, stable delivery of goods, lead- time, and production capability.

Pal, O., Gupta, A. K., and Garg, R. K. [18]: Price, quality, delivery, performance history, warranties and claims policies, production facilities and capacity, technical capability, financial position, procedural compliance, reputation and position in industry, desire for business, repair service, attitude, packaging ability, labor relations record, geographical location, amount of past business, reciprocal arrangement.

In the illustrative experiment given in Section 4, are involved: Vendor's CNC experience, and reputation of vendor/brand criteria.

\subsection{Dimensional Analysis (DA)}

Basic concepts to calculate an index of similarity by applying DA, may be defined in the following steps:

- Create a cluster of experts and define the importance of each one.

- Define the importance of each criteria in evaluation and join the opinions given by DMs.

- Create the aggregate decision matrix that represents the evaluations given by DMs for each of the alternatives

- Calculate index similarity using the following equation:

Definition 1. Ref [3]: Let $a_{l}^{k}(k=1, \ldots, n)(l=1, \ldots m)$ and $S_{l}^{*}=a_{j}^{*}(l=1, \ldots, m)$ represent a database of crisp numbers (quantitative). DA is defined as follows.

$$
I S_{i}\left(a_{1}^{i}, a_{2}^{i}, \ldots, a_{m}^{i}\right)=\prod_{j=1}^{m}\left(\frac{a_{j}^{i}}{S_{l}^{*}}\right)^{w_{j}}
$$

where $I S_{i}$ is called the index of similarity for alternative $i$.

where $a_{l}^{k}$ is the crisp evaluation of criterion $l$ for alternative $i$.

where $S_{l}^{*}$ is the crisp value of the ideal alternative for criterion $l$.

where $w_{j}(z=1, \ldots, m)$ is the crisp weight for criterion $l$

- Once the index of similarity it is obtained, rank the alternatives.

\subsection{Intuitionistic Fuzzy Set (IFS)}

Basic concepts of IFS are mentioned in the following:

Definition 2. Ref [21]: Let $X$ be a universe of discourse. Then IFS I in X is given by:

$$
I=\left\{\left\langle x, \mu_{I}(x), v_{I}(x)\right\rangle \mid x \in X\right\}
$$

where $\mu_{1}: X \rightarrow[0,1]$ denotes the degree of membership and $v_{1}: X \rightarrow[0,1]$ denotes the degree of non-membership of the element $x \in X$ to the set " $I$ ". According to $\mathrm{Zu} \mathrm{[41]} \mathrm{the}$ IFS operations presenting the basic operations like addition, division, multiplication are defined as follows; $M$ and $N$ are fuzzy set numbers:

$$
M \otimes N=\left(\mu_{M} \times \mu_{N}, v_{M}+v_{N}-v_{M} \times v_{N}\right)
$$




$$
\begin{aligned}
& \frac{M}{N}=\left(\frac{\mu_{M}}{\mu_{N}}, \frac{v_{M}-v_{N}}{1-v_{N}} \mid x \in X\right) \\
& \lambda M=\left(1-\left(1-\mu_{M}\right)^{\lambda},\left(v_{M}\right)^{\lambda}\right) \\
& M^{\lambda}=\left(\left(\mu_{M}\right)^{\lambda}, 1-\left(1-v_{M}\right)^{\lambda}\right)
\end{aligned}
$$

\subsection{Pythagorean Fuzzy Set (PFS)}

In comparison of PFS and IFS: when an expert gives the evaluation information concerning the membership grade is 0.8 and the degree of nonmembership is 0.6 , it can be observed that the IFS does not address this problem because if $0.8+0.6>1$ their sum exceeds 1, IFS fail to handle such situations [59]. However, $0.8^{2}+0.6^{2}<1$ according to the PFS is able to represent this evaluation information represented by Figure 1 [24,25,60,61].

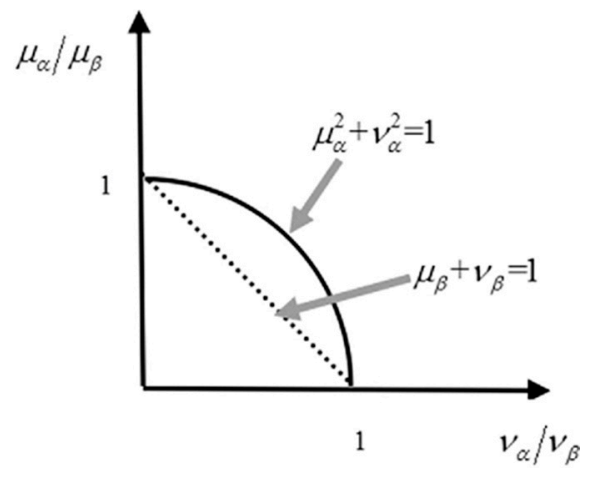

Figure 1. This graph shows the main difference for IFS vs. PFS.

Basic concepts of PFS are mentioned in the following:

Definition 3. Refs [24,25]: Let X be a universe of discourse. A PFS P in X is given by:

$$
P=\left\{\left\langle x, \mu_{P}(x), v_{P}(x)\right\rangle \mid x \in X\right\}
$$

The degree of indeterminacy [24,25] is expressed, where $\mu_{P}: X \rightarrow[0,1]$ denotes the degree of membership and $v_{P}: X \rightarrow[0,1]$ denotes the degree of non-membership of the element $x \in X$ to the set $P$. Therefore, the degree of indeterminacy is given by:

$$
\pi_{P}(x)=\sqrt{1-\left(\mu_{P}(x)\right)^{2}-\left(v_{P}(x)\right)^{2}}
$$

Definition 4. Ref [62]: for any PFS, $p=(\mu, v)$, the score is defined as follows where $s(p) \epsilon[0,1]$

$$
s(p)=(\mu)^{2}-(v)^{2}
$$

Definition 5. Refs [61,62]: if $M, N \in P F S$, then the operations are defined as follows:

$$
p^{\lambda}=\left(\mu^{\lambda}, \sqrt{\left.1-\left(1-v^{2}\right)^{\lambda}\right)}\right.
$$

where $\lambda$ is a real number $(1,2,3 \ldots n)$ that represents the power of " $p$ " that represents a Pythagorean fuzzy number or set:

$$
\lambda p=\left(\sqrt{\left.1-\left(1-\mu^{2}\right)^{\lambda}, v^{\lambda}\right)}\right.
$$


where $\lambda$ represents a real number $(1,2,3 \ldots n)$ and " $p$ " represents the Pythagorean fuzzy number or set:

$$
\begin{gathered}
M \otimes N=\left\{<x, \mu_{M}(x) \mu_{N}(x), \sqrt{v_{M}^{2}(x)+v_{N}^{2}-v_{M}^{2}(x) v_{N}^{2}(x)}\right\} \\
M \oslash N=\left\{<x, \frac{\mu_{M}(x)}{\mu_{N}(x)}, \sqrt{\frac{\mu_{M}^{2}(x)-v_{N}^{2}(x)}{1-v_{N}^{2}(x)}}\right\}
\end{gathered}
$$

\subsection{Linguistic Pythagorean Fuzzy Set (LPFS)}

Basic concepts of LPFS are mentioned in the following:

Definition 6. Refs [34]: let X be a universe of discourse. Then $\hat{S}=\left\{S_{\alpha} \mid S_{0} \leq S_{\alpha} \leq S_{t}, \alpha \in[0, t]\right\}$ is a continuous linguistic term set. A LPFS is given by:

$$
M=\left\{\left(X, S_{\theta}(x), S_{\sigma}(x)\right) \mid x \in X\right\}
$$

Then is replaced by $\left\{S_{\theta}(x), S_{\sigma}(x) \mid x \in \hat{S}\right\}$ that stands for the linguistic membership degree and linguistic nonmembership degree of element $X$ to $M$.

Definition 7. Ref [34]: Be $M=\left(S_{\theta}, S_{\sigma}\right)$ a linguistic pythagorean fuzzy value (LPFV) with $S_{\theta}, S_{\sigma}$ Ie $\hat{S}$. that represents linguistic values membership and nonmembership similar to PFS, and " $t$ " is a real number $(1,2,3 \ldots n)$ that represents the maximum value given to the linguistic labels. Therefore, the score value is given by:

$$
S(M)=\sqrt[s]{t^{2}+\theta_{1}^{2}-\sigma_{1}^{2} / 2}
$$

In addition, the accuracy value is calculated as:

$$
H(M)=\sqrt[s]{\theta_{1}^{2}-\sigma_{1}^{2}}
$$

Definition 8. Ref [34]: Let $A=\left(S_{\theta 1}, S_{\sigma 1}\right)$ and $B=\left(S_{\theta 2} S_{\sigma 2}\right)$ be LPFNs where $S_{\theta 1}, S_{\sigma 1}, S_{\theta 2}$, $S_{\sigma 2} \in \hat{S}=\left\{S_{\alpha} \mid S_{0} \leq S_{\alpha} \leq S_{t}, \alpha \in[0, t]\right\}$ with $\lambda>0$ be a real number, then operations for linguistic variables are given by:

$$
\begin{gathered}
M \oplus N=\left(\sqrt[s_{t}]{\theta_{1}^{2} / t^{2}+\theta_{2}^{2} / t^{2}-\theta_{1}^{2} \theta_{2}^{2} / t^{4}}\right), S_{t}\left(\sigma_{1} \sigma_{2} / t^{2}\right) ; \\
M \otimes N=\left(S_{t}\left(\sigma_{1} \sigma_{2} / t^{2}\right), \sqrt[s_{t}]{\theta_{1}^{2} / t^{2}+\theta_{2}^{2} / t^{2}-\theta_{1}^{2} \theta_{2}^{2} / t^{4}}\right) ; \\
\lambda M=\left(\sqrt[s_{t}]{1-\left(1-\theta_{1}^{2} / t^{2}\right)^{\lambda}}\right), S_{t}\left(\sigma_{1} / t\right)^{\lambda} ;
\end{gathered}
$$

where $\lambda$ represents a real number $(1,2,3 \ldots n)$ and " $M$ " represents the Pythagorean fuzzy number or set. On the other hand, equation

$$
M^{\lambda}=S_{t}\left(\sigma_{1} / t\right)^{\lambda},\left(\sqrt[s_{t}]{1-\left(1-\theta_{1}^{2} / t^{2}\right)^{\lambda}}\right)
$$

where $\lambda$ is a real number $(1,2,3 \ldots n)$ represents the power of " $M$ ". 
Definition 9. Ref [34]: Let $M=\left(S_{\theta i}, S_{\sigma i}\right)$ be a collection of LPFS, therefore the LPFOWA is described as follows:

$\operatorname{LPFOWA}\left(M_{1}, M_{2}, \ldots, M_{m}\right)=W_{1} M_{1} \oplus W_{2} M_{2} \oplus \ldots W_{m} M_{m}=\sqrt[s]{\left.1-\prod_{j=1}^{m}\left(1-\theta_{1}^{2} / t^{2}\right)_{i}^{W}\right)}, S_{t} \prod_{i=j}^{m}\left(\sigma_{i} / t\right)_{i}^{W}$

where $\left(M_{1}, M_{2} \ldots, M_{m}\right)$ represents a set of decision makers, theta represents membership, sigma represents nonmembership given by linguistic variables, " $s$ " represents the power, " $S$ " represents a universe of linguistic set, and " $w$ " represents weight.

\section{The Proposed Model}

In this section we present the methodology that considers the integration of DA and LPFS called dimensional analysis under linguistic Pythagorean fuzzy set (DA-LPFS), which is defined for dealing with both types of information.

In order to become operative DA on LPFS we develop the following equation based on PFS and LPFS in Equations (12), (13) and (18):

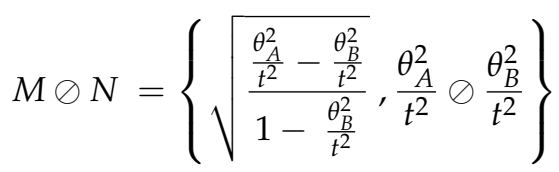

Its process is visualized in Figure 2, and the specific procedure is as follows:

- Step 1: Using the LPFS terms, construct decision matrix that represents the evaluations based on the opinions of the DMs for each of the alternatives.

- Step 2: In order to aggregate the opinions of DMs in a single decision matrix we utilize the LPFOWA Equation (21) defined in Section 2.4.

- Step 3: Select ideal solution in accordance with benefit (BN) or cost (C) criteria values.

- Step 4: Standardized matrix. In this step we take equation (22).

- Step 5: Standardized matrix elevated in accordance with criteria weights. In this step we take the Equation (19) in Section 2.4.

- Step 6: Generate LPFIS index, use the product Equation (18) in Section 2.4.

- Step 7: Establish the highest index of IS, use score Equation (15) in Section 2.4.

- Step 8: Arrange the score function of all the alternatives in descending order and select the alternative that has the highest score function value.

In the following we present a diagram (Figure 2):

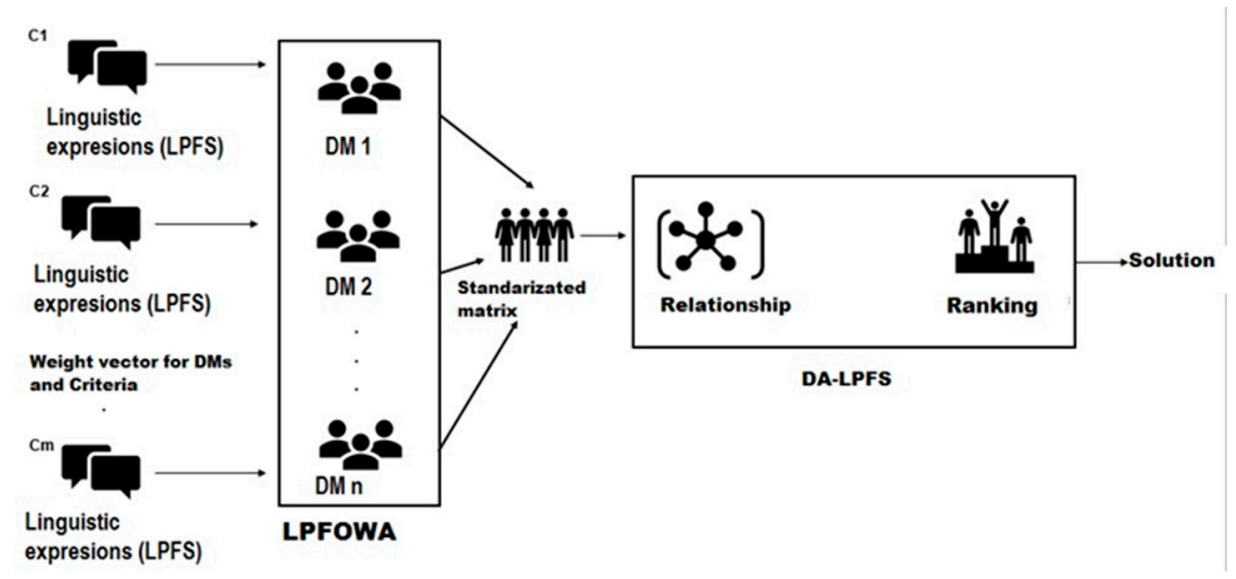

Figure 2. DA-LPFS diagram. 


\section{Illustrative Example}

\subsection{An Illustrative Experiment with DA-LPFS}

In this section, the proposed DA-LPFS model will be implemented on a CNC router selection for a manufacturing system.

$\mathrm{CNC}$ router machines can produce parts with high precision, therefore it is important to select the most appropriate according to the productivity and flexibility, hence, a decision making process is needed to avoid a wrong investment [63]. For this, they have considered three possible brands (A1, A2, A3) after their preliminary review. Furthermore, they have taken into evaluation each alternative under the following characteristics:

- $\quad \mathrm{CNC}$ router construction (C1);

- Process design (C2);

- Performance (C3);

- $\quad$ CNC computer system (C4);

- Adaptation of workers (C5);

- Worker technical capability needed (C6);

- Initial cost (C7);

- $\quad$ Running cost (C8);

- Vendor's CNC experience (C9);

- Reputation of vendor/brand (C11).

The weight vector of the 11 attributes is $\mathrm{W}=(0.0404,0.0154,0.1173,0.2538,0.0827$, $0.0923,0.0692,0.0769,0.0308,0.0692)$ that were calculated using the entropy measures [64]. The two experts D1, D2, were invited to provide their preferences for each alternative and each attribute in evaluation with the linguistic term set: $\mathrm{S}=\mathrm{S} 0=$ extremely-poor, S1 = very-poor, S2 = poor, S3 = slightly-poor, S4 = fair, S5 = slightly-good, S6 = good, S7 = very-good, S8 = extremely-good [63]. Then, we utilized the above-proposed operators to get the most desirable alternative(s) as follows:

Step 1: The preferences of two experts over each alternative are summarized in the form of the decision matrix Table $1 \mathrm{a}, \mathrm{b}$ and Table $2 \mathrm{a}, \mathrm{b}$ :

$$
\left[R_{K}\right]=\left[a_{i j}\right]^{k}(3 \times 11)
$$

Table 1. The fuzzy linguistic judgment-matrix provided by DM1.

\begin{tabular}{|c|c|c|c|c|c|c|}
\hline \multicolumn{7}{|c|}{ (a) } \\
\hline Alt & $\mathrm{C} 1$ & C2 & C3 & C4 & \multicolumn{2}{|c|}{ C5 } \\
\hline A1 & $\{\mathrm{S} 6, \mathrm{~S} 1\}$ & $\{\mathrm{S} 3, \mathrm{~S} 1\}$ & $\{\mathrm{S} 3, \mathrm{~S} 3\}$ & $\{\mathrm{S} 1, \mathrm{~S} 6\}$ & \multicolumn{2}{|c|}{$\mathrm{S} 3, \mathrm{~S} 4$} \\
\hline A2 & $\{\mathrm{S} 6, \mathrm{~S} 1\}$ & $\{\mathrm{S} 6, \mathrm{~S} 2\}$ & $\{\mathrm{S} 4, \mathrm{~S} 3\}$ & $\{\mathrm{S} 5, \mathrm{~S} 1\}$ & \multirow{2}{*}{\multicolumn{2}{|c|}{$\begin{array}{l}\{\mathrm{S} 7, \mathrm{~S} 1\} \\
\{\mathrm{S} 6, \mathrm{~S} 1\}\end{array}$}} \\
\hline A3 & $\{\mathrm{S} 1, \mathrm{~S} 6\}$ & $\{\mathrm{S} 3, \mathrm{~S} 4\}$ & $\{\mathrm{S} 3, \mathrm{~S} 4\}$ & $\{\mathrm{S} 3, \mathrm{~S} 2\}$ & & \\
\hline \multicolumn{7}{|c|}{ (b) } \\
\hline Alt & C6 & C7 & C8 & C9 & C10 & C11 \\
\hline A1 & $\{\mathrm{S} 3, \mathrm{~S} 4\}$ & $\{\mathrm{S} 2, \mathrm{~S} 5\}$ & $\{\mathrm{S} 2, \mathrm{~S} 4\}$ & $\{\mathrm{S} 1, \mathrm{~S} 3\}$ & $\{\mathrm{S} 2, \mathrm{~S} 3\}$ & $\{\mathrm{S} 3, \mathrm{~S} 2\}$ \\
\hline A2 & $\{\mathrm{S} 1, \mathrm{~S} 3\}$ & $\{\mathrm{S} 2, \mathrm{~S} 3\}$ & $\{\mathrm{S} 3, \mathrm{~S} 2\}$ & $\{\mathrm{S} 3, \mathrm{~S} 4\}$ & $\{\mathrm{S} 2, \mathrm{~S} 5\}$ & $\{\mathrm{S} 2, \mathrm{~S} 4\}$ \\
\hline A3 & $\{\mathrm{S} 3, \mathrm{~S} 1\}$ & $\{\mathrm{S} 3, \mathrm{~S} 3\}$ & $\{\mathrm{S} 2, \mathrm{~S} 4\}$ & $\{\mathrm{S} 1, \mathrm{~S} 3\}$ & $\{\mathrm{S} 1, \mathrm{~S} 6\}$ & $\{\mathrm{S} 1, \mathrm{~S} 3\}$ \\
\hline
\end{tabular}


Table 2. The fuzzy linguistic judgment-matrix provided by DM2.

\begin{tabular}{|c|c|c|c|c|c|c|}
\hline & & & (a) & & & \\
\hline Alt & $\mathrm{C} 1$ & $\mathrm{C} 2$ & $\mathrm{C} 3$ & $\mathrm{C} 4$ & \multicolumn{2}{|c|}{ C5 } \\
\hline A1 & $\{\mathrm{S} 2, \mathrm{~S} 3\}$ & $\{S 6, S 7\}$ & $\{\mathrm{S} 3, \mathrm{~S} 4\}$ & $\{\mathrm{S} 2, \mathrm{~S} 3\}$ & \multicolumn{2}{|c|}{$S 5, S 2$} \\
\hline A2 & $\{\mathrm{S} 5, \mathrm{~S} 3\}$ & $\{\mathrm{S} 5, \mathrm{~S} 2\}$ & $\{\mathrm{S} 3, \mathrm{~S} 3\}$ & $\{\mathrm{S} 5, \mathrm{~S} 2\}$ & \multicolumn{2}{|c|}{$S 4, S 1$} \\
\hline A3 & $\{\mathrm{S} 5, \mathrm{~S} 2\}$ & $\{\mathrm{S} 2, \mathrm{~S} 1\}$ & $\{\mathrm{S} 3, \mathrm{~S} 4\}$ & $\{\mathrm{S} 1, \mathrm{~S} 2\}$ & \multicolumn{2}{|c|}{$\mathrm{S} 4, \mathrm{~S} 1$} \\
\hline \multicolumn{7}{|c|}{ (b) } \\
\hline Alt & C6 & $\mathrm{C} 7$ & $\mathrm{C} 8$ & C9 & C10 & C11 \\
\hline A1 & $\{\mathrm{S} 2, \mathrm{~S} 1\}$ & $\{S 3, S 4\}$ & $\{S 2, S 5\}$ & $\{\mathrm{S} 2, \mathrm{~S} 3\}$ & $\{\mathrm{S} 3, \mathrm{~S} 3\}$ & $\{\mathrm{S} 1, \mathrm{~S} 2\}$ \\
\hline A2 & $\{\mathrm{S} 2, \mathrm{~S} 3\}$ & $\{S 3, S 3\}$ & $\{S 6, S 7\}$ & $\{\mathrm{S} 3, \mathrm{~S} 3\}$ & $\{\mathrm{S} 5, \mathrm{~S} 2\}$ & $\{\mathrm{S} 3, \mathrm{~S} 4\}$ \\
\hline A3 & $\{\mathrm{S} 3, \mathrm{~S} 4\}$ & $\{\mathrm{S} 2, \mathrm{~S} 3\}$ & $\{\mathrm{S} 5, \mathrm{~S} 2\}$ & $\{\mathrm{S} 5, \mathrm{~S} 2\}$ & $\{\mathrm{S} 3, \mathrm{~S} 3\}$ & $\{\mathrm{S} 5, \mathrm{~S} 2\}$ \\
\hline
\end{tabular}

Step 2: The weight vector concerning with each DM: $W=(0.51,0.49)$ was calculated using the entropy measures [46]. Then, the LPFOWA operator was utilized to develop the aggregate decision matrix in Table $3 a, b$ :

$$
[R]=\left[R_{i j}\right](3 x 11)
$$

Table 3. Aggregated matrix value R using LPFOWA operator.

\begin{tabular}{|c|c|c|c|c|c|c|}
\hline \multicolumn{7}{|c|}{ (a) } \\
\hline Alt & $\mathrm{C} 1$ & $\mathrm{C} 2$ & $\mathrm{C} 3$ & $\mathrm{C} 4$ & \multicolumn{2}{|c|}{ C5 } \\
\hline A1 & $\{3.58,1.71\}$ & $\{6.00,2.59\}$ & $\{3.00,3.45\}$ & $\{1.58,4.27\}$ & \multicolumn{2}{|c|}{$4.31,2.85$} \\
\hline A2 & $\{4.31,1.71\}$ & $\{4.59,2.00\}$ & $\{3.58,3.00\}$ & $\{5.00,1.40\}$ & \multicolumn{2}{|c|}{$2.31,1.00$} \\
\hline A3 & $\{4.17,3.50\}$ & $\{2.57,2.03\}$ & $\{3.00,4.00\}$ & $\{2.31,2.00\}$ & \multicolumn{2}{|c|}{$2.58,1.00$} \\
\hline \multicolumn{7}{|c|}{ (b) } \\
\hline Alt & C6 & $\mathrm{C} 7$ & $\mathrm{C} 8$ & C9 & C10 & C11 \\
\hline A1 & $\{2.58,2.02\}$ & $\{2.56,4.48\}$ & $\{2.00,4.46\}$ & $\{1.58,3.00\}$ & $\{2.56,3.00\}$ & $\{2.31,2.00\}$ \\
\hline A2 & $\{1.58,3.00\}$ & $\{2.56,3.00\}$ & $\{6.00,3.69\}$ & $\{3.00,3.47\}$ & $\{4.21,3.19\}$ & $\{2.56,4.00\}$ \\
\hline A3 & $\{3.00,1.97\}$ & $\{2.58,3.00\}$ & $\{4.12,2.84\}$ & $\{4.01,2.45\}$ & $\{2.27,4.27\}$ & $\{4.01,2.45\}$ \\
\hline
\end{tabular}

Step 3: Establish the ideal solution in accordance with criteria values in Table 4a,b:

Table 4. Ideal solution.

\begin{tabular}{cccccc}
\hline \multicolumn{7}{c}{ (a) } \\
C1 & C2 & C3 & C4 & \multicolumn{2}{c}{ C5 } \\
\hline$\{4.18,3.50\}$ & $\{5.26,2.02\}$ & $\{4.84,4.00\}$ & $\{5.62,4.27\}$ & \multicolumn{2}{c}{$3.11,2.84$} \\
\hline \multicolumn{7}{c}{ C6 } & \multicolumn{2}{c}{ (b) } & C9 & C10 & C11 \\
\hline$\{5.62,3.00\}$ & $\{5.05,3.00\}$ & $\{3.25,2.85\}$ & $\{4.84,3.47\}$ & $\{5.17,4.27\}$ & $\{5.05,4.00\}$ \\
\hline
\end{tabular}

Step 4: Standardize the aggregate decision matrix (Table 5a,b). 
Table 5. Standardized matrix.

\begin{tabular}{|c|c|c|c|c|c|c|}
\hline \multicolumn{7}{|c|}{ (a) } \\
\hline Alt & $\mathrm{C} 1$ & $\mathrm{C} 2$ & C3 & $\mathrm{C} 4$ & \multicolumn{2}{|c|}{ C5 } \\
\hline A1 & $\{0.49,0.49\}$ & $\{1.00,1.28\}$ & $\{0.00,0.86\}$ & $\{1.00,0.00\}$ & \multicolumn{2}{|c|}{$0.00,1.00$} \\
\hline A2 & $\{0.25,0.49\}$ & $\{0.70,0.99\}$ & $\{0.37,0.75\}$ & $\{0.81,0.33\}$ & \multicolumn{2}{|c|}{$0.88,0.35$} \\
\hline A3 & $\{0.00,1.00\}$ & $\{0.00,1.00\}$ & $\{0.00,1.00\}$ & $\{0.29,0.47\}$ & \multicolumn{2}{|c|}{$0.83,0.35$} \\
\hline \multicolumn{7}{|c|}{ (b) } \\
\hline Alt & C6 & $\mathrm{C} 7$ & $\mathrm{C} 8$ & C9 & C10 & C11 \\
\hline A1 & $\{0.35,0.68\}$ & $\{0.00,0.67\}$ & $\{0.64,0.64\}$ & $\{0.49,0.86\}$ & $\{0.21,0.70\}$ & $\{0.20,0.50\}$ \\
\hline A2 & $\{0.00,1.00\}$ & $\{0.00,1.00\}$ & $\{1.00,0.77\}$ & $\{0.00,1.00\}$ & $\{0.62,0.75\}$ & $\{0.00,1.00\}$ \\
\hline A3 & $\{0.44,0.66\}$ & $\{0.05,1.00\}$ & $\{1.00,1.00\}$ & $\{0.51,0.71\}$ & $\{0.00,1.00\}$ & $\{0.57,0.61\}$ \\
\hline
\end{tabular}

Step 5: Standardized matrix elevated with criteria weights using entropy (Table 6a,b).

Table 6. Standardized matrix with entropy weights.

\begin{tabular}{|c|c|c|c|c|c|c|}
\hline \multicolumn{7}{|c|}{ (a) } \\
\hline Alt & $\mathrm{C} 1$ & $\mathrm{C} 2$ & $\mathrm{C} 3$ & $\mathrm{C} 4$ & \multicolumn{2}{|c|}{$\mathrm{C} 5$} \\
\hline A1 & $\{0.90,0.28\}$ & $\{0.97,0.18\}$ & $\{0.00,0.56\}$ & $\{0.00,1.00\}$ & \multicolumn{2}{|c|}{$0.00,1.00$} \\
\hline A2 & $\{0.88,0.28\}$ & $\{0.96,0.28\}$ & $\{0.72,0.51\}$ & $\{0.60,0.62\}$ & \multicolumn{2}{|c|}{$0.85,0.38$} \\
\hline A3 & $\{0.00,1.00\}$ & $\{0.00,1.00\}$ & $\{0.00,1.00\}$ & $\{0.46,0.64\}$ & \multicolumn{2}{|c|}{$0.85,0.38$} \\
\hline \multicolumn{7}{|c|}{ (b) } \\
\hline Alt & C6 & $\mathrm{C} 7$ & $\mathrm{C} 8$ & C9 & C10 & C11 \\
\hline A1 & $\{0.65,0.55\}$ & $\{0.00,0.44\}$ & $\{0.85,0.38\}$ & $\{0.82,0.46\}$ & $\{0.90,0.27\}$ & $\{0.79,0.37\}$ \\
\hline A2 & $\{0.00,1.00\}$ & $\{0.00,1.00\}$ & $\{0.00,0.41\}$ & $\{0.00,1.00\}$ & $\{0.93,0.28\}$ & $\{0.00,1.00\}$ \\
\hline A3 & $\{0.67,0.55\}$ & $\{0.65,1.00\}$ & $\{0.00,1.00\}$ & $\{0.83,0.42\}$ & $\{0.00,1.00\}$ & $\{0.85,0.38\}$ \\
\hline
\end{tabular}

Step 6: Generate an index of similarity, LPFIS (Table 7).

Table 7. LPFS index.

\section{IS}

$0,0.010554$
$0,0.028211$
$0,0.011850$

Step 7: Obtain the highest index of similarity (Table 8).

Table 8. Index of similarity and ranking.

\begin{tabular}{cc}
\hline IS & Rank \\
\hline 4.242634 & 1 \\
4.242594 & 3 \\
4.242632 & 2 \\
\hline
\end{tabular}

\subsection{Sensitivity Analysis}

To further show the advantages and contributions of this paper, a comparative analysis is given below. A sensitivity analysis is given in order to check consistency, and robustness of solutions [65]. On the other hand, it can be defined as stability or behavior of the solution to small changes [66].

With the weight vector given in the literature [63] $\mathrm{W}=(0.141,0.096,0.129,0.087,0.124$, $0.019,0.18,0.094,0.019,0.056,0.056)$, we obtained the following ranking (Table 9): 
Table 9. Ranking with weight vector by literature.

\begin{tabular}{cc}
\hline IS & Rank \\
\hline 4.24264 & 1 \\
4.24259 & 3 \\
4.24263 & 2 \\
\hline
\end{tabular}

We inverted the weight vector calculated by entropy [64] and we obtained the following ranking (Table 10):

Table 10. Ranking with inverted weight vector by entropy.

\begin{tabular}{cc}
\hline IS & Rank \\
\hline 4.24634 & 1 \\
4.24594 & 3 \\
4.24632 & 2 \\
\hline
\end{tabular}

In the same way as the previous vector, we inverted the weights given in the literature [63] and we obtained the following ranking (Table 11):

Table 11. Ranking with inverted weight vector by literature.

\begin{tabular}{cc}
\hline IS & Rank \\
\hline 4.242628 & 1 \\
4.242594 & 3 \\
4.242626 & 2 \\
\hline
\end{tabular}

We proved assigning the same weight 0.9090 to the 11 criteria, and we obtained the following ranking (Table 12):

Table 12. Ranking with the same weight to the 11 criteria.

\begin{tabular}{cc}
\hline IS & Rank \\
\hline 4.242628 & 1 \\
4.242594 & 3 \\
4.242626 & 2 \\
\hline
\end{tabular}

The following graphic shows the behavior with the weight changes mentioned above, they have the same tendency and rankings represented by Figure 3.

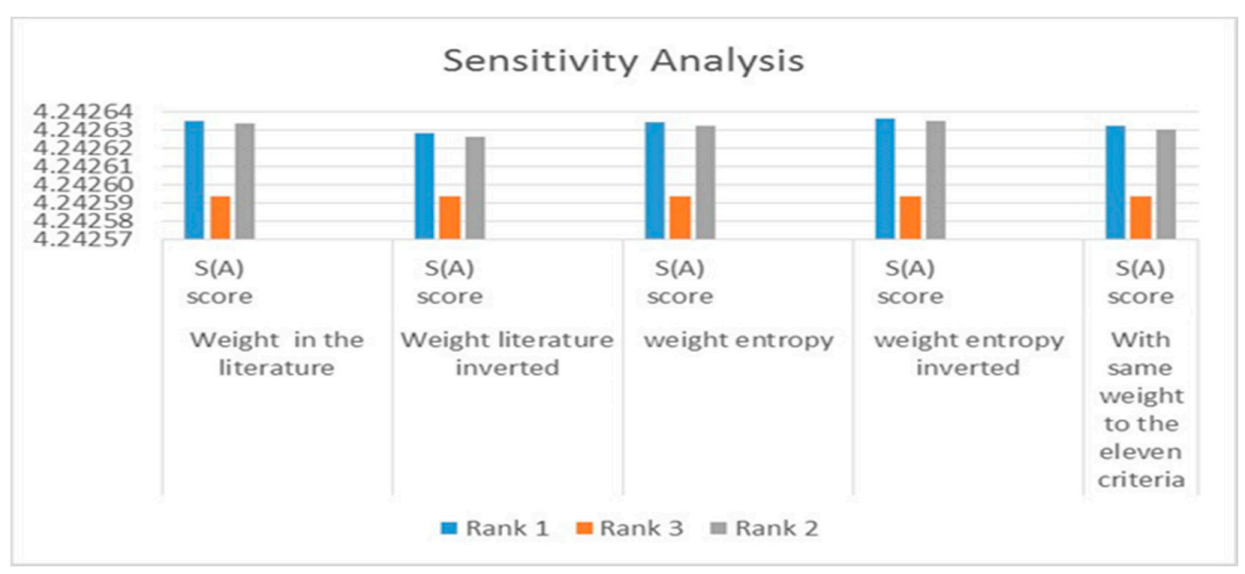

Figure 3. LPFS-DA diagram. 


\section{Discussion}

In this section we present a comparison versus other similar LPFS. Security evaluation of computer systems was a suggested problem for TOPSIS-LPFS application [67]. In the following Table 13 we present the comparison of rankings given by TOPSIS-LPFS and that calculated for DA-LPFS represented by Figure 4.

Table 13. Spearman correlation calculation for LPFS-DA and LPFS-TOPSIS.

\begin{tabular}{ccccc}
\hline ALT & DA-LPFS Ranking & TOPSIS-LPFS Ranking & $\mathbf{d}$ & $\mathbf{d}^{\mathbf{2}}$ \\
\hline A1 & 3 & 5 & 2 & 4 \\
A2 & 1 & 3 & 2 & 4 \\
A3 & 4 & 1 & 3 & 9 \\
A4 & 3 & 4 & 1 & 1 \\
A5 & 2 & 2 & 0 & 0 \\
\hline
\end{tabular}

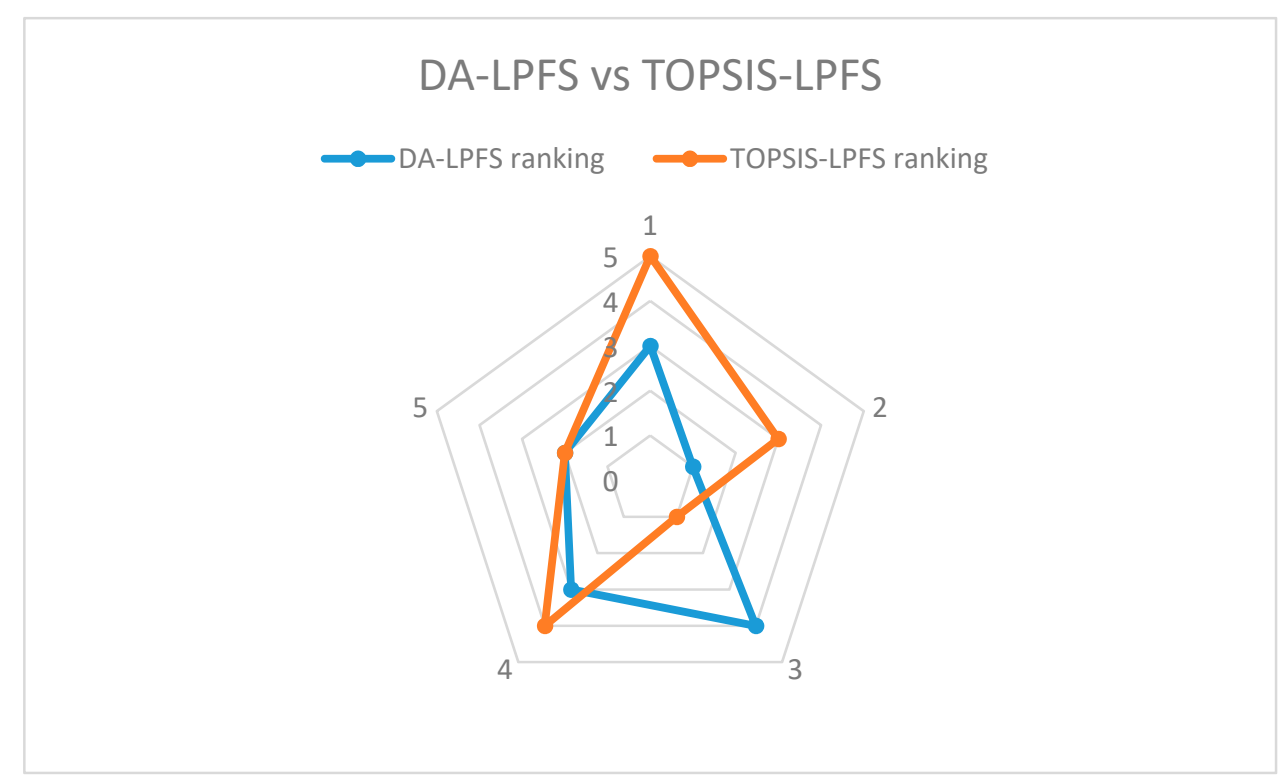

Figure 4. Rankings for LPFS-DA and LPFS-TOPSIS.

Then we used Spearman correlation [68] in order to calculate the correlation among both methods, then we had:

$$
\sum_{i=1}^{n} d_{i}^{2}=18 \quad r_{s}=1-\frac{6 \times 18}{5^{3}-5}=0.1
$$

The result shows that for the Spearman correlation 0.1 there is no substantial correspondence between LPFS-DA and LPFS-TOPSIS. However, the ordinary TOPSIS method is based on distance between each alternative and ideal solution [34] but does not consider the relationships among criteria, on the other hand, ordinary DA has the characteristic to integrate the opinions given by experts, involves alternatives and mutual criteria relationship and its importance [3].

\section{Conclusions}

In this paper, we investigated the MCDM problems with quantitative and qualitative information to solve a $\mathrm{CNC}$ router selection problem. The main advantage/benefit to use DA is the characteristic to consider the mutual relationship about criteria and is recommended for the assessment of alternatives. Furthermore, LPFS is an extended version of PFS as it is able to represent evaluation information better than IFS that fails in some situations $[24,25,59-61]$. The main contributions of this paper are summarized as follows: 
we utilized DA under LPFS environment, LPFOWA operator for gathering data for more than one decision maker, and entropy measures for calculating weights. Compared with other methods, our method is able to gather all these tools using their better characteristics of DA and LPFS and has a robust method which is the main strength.

Finally, we presented an application to demonstrate the proposed method. It can be said that there is an opportunity to continue developing research in the LPFS, therefore, it is proposed to obtain a method that has the ability to manipulate crisp and diffuse information, since generally both types of information are present in multicriteria problems, specifically in supplier's selection. For future work we recommend applying this method in other areas different to the selection of suppliers or machinery, and compare with other similar methods with LPFS extension. In addition, we recommend developing a program that allows to capture linguistic labels and process the information. Computing with words is another approach that is intended to deal with quantitative and qualitative factors [26-32].

Author Contributions: Data curation A.J.V.S.; Formal analysis, L.P.-D.; Investigation, L.P.-D.; Methodology, A.J.V.S.; Project administration, E.M.G.; Resources, E.M.G.; Supervision, D.L.-C., D.V.-R.; Validation, A.J.V.S.; Visualization, D.L.-C.; Writing—original draft, A.J.V.S.; Writing-review and editing, A.J.V.S., L.P.-D. All authors have read and agreed to the published version of the manuscript.

Funding: This research was funded by Consejo Nacional De Ciencia Y Tecnologia (Conacyt), No. CVU: 659942.

Institutional Review Board Statement: Not applicable.

Informed Consent Statement: Not applicable.

Data Availability Statement: Not applicable.

Conflicts of Interest: The authors declare no conflict of interest.

\section{References}

1. Gibbings, J. Dimensional Analysis; Springer: Berlin/Heidelberg, Germany, 2011; pp. 1-297.

2. Buckingham, E. On Physically Similar Systems; Illustrations of the Use of Dimensional Equations. Phys. Rev. 1914, 4, 345-376. [CrossRef]

3. Perez-Dominguez, L.; Alvarado-Iniesta, A.; García-Alcaraz, J.L.; Valles-Rosales, D.J. Intuitionistic fuzzy dimensional analysis for multi-criteria decision making. Iran. J. Fuzzy Syst. 2018, 15, 17-40.

4. Vignaux, G.A. Dimensional Analysis in Operations-Research. N. Z. Oper. Res. 1986, 14, 81-92.

5. Huntley, H.E. Dimensional Analysis; Rinehart and Company: New York, NY, USA, 1951.

6. Naddor, E. Dimensions in Operations Research. Oper. Res. 1966, 14, 508-514. [CrossRef]

7. Gardner, E.S. Dimensional Analysis of Airline Quality. Interfaces 2004, 34, 272-279. [CrossRef]

8. Willis, T.; Huston, C.; Pohlkamp, F. Evaluation measures of just in-time supplier performance. Prod. Inventory Manag. J. 1993, 34, $1-6$.

9. Humphreys, P.; Mak, K.L.; McIvor, R. Procurement. Logist. Inf. Manag. 1998, 11, 28-37. [CrossRef]

10. Li, C.C.; Fun, Y.P. A new measure for supplier performance evaluation. Iie Trans. 1997, 29, 753-758. [CrossRef]

11. Braglia, M.; Gabbrielli, R. Dimensional analysis for investment selection in industrial robots. Int. J. Prod. Res. 2000, 38, 4843-4848. [CrossRef]

12. Liang, J.; Neng, H.; Tzeng, G.; Huei, R. Vendor selection by integrated fuzzy MCDM techniques with independent and interdependent relationships. Inf. Sci. 2008, 178, 4166-4183.

13. Carney, D.J.; Wallnau, K.C. A basis for evaluation of commercial software. Inf. Softw. Technol. 1998, 40, 851-860. [CrossRef]

14. Hsu, C.-C. Evaluation criteria for blog design and analysis of causal relationships using factor analysis and DEMATEL. Expert Syst. Appl. 2012, 39, 187-193. [CrossRef]

15. Namin, F.S.; Shahriar, K.; Bascetin, A.; Ghodsypour, S.H. FMMSIC: A hybrid fuzzy based decision support system for MMS (in order to estimate interrelationships between criteria). J. Oper. Res. Soc. 2012, 63, 218-231. [CrossRef]

16. Qin, Y.; Cui, X.; Huang, M.; Zhong, Y.; Tang, Z.; Shi, P. Archimedean Muirhead Aggregation Operators of q-Rung Orthopair Fuzzy Numbers for Multicriteria Group Decision Making. Complexity 2019, 2019, 1-33. [CrossRef]

17. Tsao, C.-T. A fuzzy MCDM approach for stock selection. J. Oper. Res. Soc. 2006, 57, 1341-1352. [CrossRef]

18. Pal, O.; Gupta, A.K.; Garg, R.K. Supplier selection criteria and methods in supply chains: A review. International Journal of Social, Management. Econ. Bus. Eng. 2013, 7, 1403-1409.

19. Saad, R.M.; Ahmad, M.Z.; Abu, M.S.; Jusoh, M.S. Hamming Distance Method with Subjective and Objective Weights for Personnel Selection. Sci. World J. 2014, 2014, 865495. [CrossRef] [PubMed] 
20. Zadeh, L.A. Fuzzy sets. Inf. Control 1965, 8, 338-353. [CrossRef]

21. Atanassov, K.T. Intuitionistic fuzzy sets. Fuzzy Sets Syst. 1986, 20, 87-96. [CrossRef]

22. Mardani, A.; Jusoh, A.; Zavadskas, E.K. Fuzzy multiple criteria decision-making techniques and applications-Two decades review from 1994 to 2014. Expert Syst. Appl. 2015, 42, 4126-4148. [CrossRef]

23. Zhang, Q. Fuzziness-vagueness-generality-ambiguity. J. Pragmat. 1998, 29, 13-31. [CrossRef]

24. Yager, R.R. Pythagorean Membership Grades in Multicriteria Decision Making. IEEE Trans. Fuzzy Syst. 2013, 22, 958-965. [CrossRef]

25. Yager, R.R.; Abbasov, A.M. Pythagorean Membership Grades, Complex Numbers, and Decision Making. Int. J. Intell. Syst. 2013, 28, 436-452. [CrossRef]

26. Mart, L. Computing with Words in Decision support Systems: An overview on Models and Applications. Int. J. Comput. Intell. Syst. 2010, 3, 382-395.

27. Herrera, F.; Herrera-Viedma, E. Linguistic decision analysis: Steps for solving decision problems under linguistic infor-mation. Fuzzy Sets Syst. 2000, 115, 67-82. [CrossRef]

28. Zadeh, L. From computing with numbers to computing with words. From manipulation of measurements to manipulation of perceptions. IEEE Trans. Circuits Syst. I Regul. Pap. 1999, 46, 105-119. [CrossRef]

29. Herrera, F.; Alonso, S.; Chiclana, F.; Herrera-Viedma, E. Computing with words in decision making: Foundations, trends and prospects. Fuzzy Optim. Decis. Mak. 2009, 8, 337-364. [CrossRef]

30. Rodr, R.M.; Mart, L. Computing with Comparative Linguistic Expressions and Symbolic Translation for Decision Making: ELICIT Information. IEEE Trans. Fuzzy Syst. 2019, 6706, 1-19.

31. La, Z. Fuzzy logic computing with words. IEEE Trans. Fuzzy Syst. 1996, 4, 103-111.

32. Riera, J.V.; Torrens, J. Aggregation of subjective evaluations based on discrete fuzzy numbers. Fuzzy Sets Syst. 2012, 191, 21-40. [CrossRef]

33. Rong, Y.; Pei, Z.; Liu, Y. Linguistic Pythagorean Einstein Operators and Their Application to Decision Making. Information 2020, 11, 46. [CrossRef]

34. Garg, H. Linguistic Pythagorean fuzzy sets and its applications in multiattribute decision-making process. Int. J. Intell. Syst. 2018, 33, 1234-1263. [CrossRef]

35. Liu, Y.; Liu, J.; Qin, Y. Pythagorean fuzzy linguistic Muirhead mean operators and their applications to multiattribute decisionmaking. Int. J. Intell. Syst. 2019, 35, 300-332. [CrossRef]

36. Xian, S.; Liu, Z.; Gou, X.; Wan, W. Interval 2-tuple Pythagorean fuzzy linguistic MULTIMOORA method with CIA and their application to MCGDM. Int. J. Intell. Syst. 2020, 35, 650-681. [CrossRef]

37. Lin, M.; Huang, C.; Xu, Z. TOPSIS Method Based on Correlation Coefficient and Entropy Measure for Linguistic Pythagorean Fuzzy Sets and Its Application to Multiple Attribute Decision Making. Complexity 2019, 2019, 6967390. [CrossRef]

38. Wang, J.; Wei, G.; Gao, H. Approaches to Multiple Attribute Decision Making with Interval-Valued 2-Tuple Linguistic Pythagorean Fuzzy Information. Mathematics 2018, 6, 201. [CrossRef]

39. Huang, Y.H.; Wei, G.W. TODIM method for pythagorean 2-tuple linguistic multiple attribute decision making. J. Intell. Fuzzy Syst. 2018, 35, 901-915. [CrossRef]

40. Farzad, T.; Mohammad Rasid, O.; Aidy, A.; Rosnah Mohd, Y. A Review of Supplier Selection Methods in Manufacturing Industries. Suranaree J. Sci. Technol. 2008, 15, 201-208.

41. Chen, C.-T.; Lin, C.-T.; Huang, S.-F. A fuzzy approach for supplier evaluation and selection in supply chain management. Int. J. Prod. Econ. 2006, 102, 289-301. [CrossRef]

42. Sun, L.; Dong, H.; Liu, A.X. Aggregation Functions Considering Criteria Interrelationships in Fuzzy Multi-Criteria Decision Making: State-of-the-Art. IEEE Access 2018, 6, 68104-68136. [CrossRef]

43. Wei, G.; Lu, M.; Alsaadi, F.E.; Hayat, T.; Alsaedi, A. Pythagorean 2-tuple linguistic aggregation operators in multiple attribute decision making. J. Intell. Fuzzy Syst. 2017, 33, 1129-1142. [CrossRef]

44. Alam, K.A.; Ahmed, R.; Butt, F.S.; Kim, S.-G.; Ko, K.-M. An Uncertainty-aware Integrated Fuzzy AHP-WASPAS Model to Evaluate Public Cloud Computing Services. Procedia Comput. Sci. 2018, 130, 504-509. [CrossRef]

45. Liu, H.C.; Quan, M.Y.; Li, Z.; Wang, Z.L. A new integrated MCDM model for sustainable supplier selection under inter-val-valued intuitionistic uncertain linguistic environment. Inf. Sci. 2019, 486, 254-270. [CrossRef]

46. Kannan, V.R.; Tan, K.C. Supplier Selection and Assessment: Their Impact on Business Performance. J. Supply Chain Manag. 2002, 38, 11-21. [CrossRef]

47. Nielsen, I.E.; Banaeian, N.; Golińska, P.; Mobli, H.; Omid, M. Green Supplier Selection Criteria: From a Literature Review to a Flexible Framework for Determination of Suitable Criteria. In Smart and Sustainable Supply Chain and Logistics Trends, Challenges, Methods and Best Practices; Springer International Publishing: Cham, Switzerland, 2014; pp. 79-99. [CrossRef]

48. Dickson, G.W. An Analysis of Vendor Selection Systems and Decisions. J. Purch. 1966, 2, 5-17. [CrossRef]

49. Weber, C.A.; Current, J.R.; Benton, W. Vendor selection criteria and methods. Eur. J. Oper. Res. 1991, 50, 2-18. [CrossRef]

50. Kar, A.K.; Pani, A.K. Exploring the importance of different supplier selection criteria. Manag. Res. Rev. 2014, 37, 89-105. [CrossRef]

51. Swift, C.O. Preferences for single sourcing and supplier selection criteria. J. Bus. Res. 1995, 32, 105-111. [CrossRef]

52. Lehmann, D.R.; O'Shaughnessy, J. Decision Criteria Used in Buying Different Categories of Products. J. Purch. Mater. Manag. 1982, 18, 9-14. [CrossRef] 
53. Ansari, A.; Modarress, B. Just-In-Time Purchasing: Problems and Solutions. J. Purch. Mater. Manag. 1986, 22, 11-15. [CrossRef]

54. Spekman, R.E. Strategic supplier selection: Understanding long-term buyer relationships. Bus. Horiz. 1988, 31, 75-81. [CrossRef]

55. Wilson, E.J. The Relative Importance of Supplier Selection Criteria: A Review and Update. Int. J. Purch. Mater. Manag. 1994, 30, 34-41. [CrossRef]

56. Doney, P.M.; Cannon, J.P. An examination of the nature of trust in buyer-seller relationships. J. Mark. 1997, 61, 35-51.

57. Verma, R.; Pullman, M.E. An analysis of the supplier selection process. Omega 1998, 26, 739-750. [CrossRef]

58. Chang, B.; Chang, C.-W.; Wu, C.-H. Fuzzy DEMATEL method for developing supplier selection criteria. Expert Syst. Appl. 2011, 38, 1850-1858. [CrossRef]

59. Hussain, A.; Mahmood, T.; Ali, M.I. Rough Pythagorean fuzzy ideals in semigroups. Comput. Appl. Math. 2019, 38, 67. [CrossRef]

60. Tang, X.; Wei, G. Models for Green Supplier Selection in Green Supply Chain Management with Pythagorean 2-Tuple Linguistic Information. IEEE Access 2018, 6, 1. [CrossRef]

61. Peng, X.D.; Yang, Y. Some Results for Pythagorean Fuzzy Sets. Int. J. Intell. Syst. 2015, 30, 1133-1160. [CrossRef]

62. Zhang, X.L.; Xu, Z.S. Extension of TOPSIS to multiple criteria decision making with Pythagorean fuzzy sets. Int. J. Intell. Syst. 2014, 29, 1061-1078. [CrossRef]

63. Camci, A.; Temur, G.T.; Beskese, A. CNC router selection for SMEs in woodwork manufacturing using hesitant fuzzy AHP method. J. Enterp. Inf. Manag. 2018, 31, 529-549. [CrossRef]

64. Farhadinia, B. Multiple criteria decision-making methods with completely unknown weights in hesitant fuzzy linguistic term setting. Knowl. Based Syst. 2016, 93, 135-144. [CrossRef]

65. Yazdani, M.; Zavadskas, E.K.; Ignatius, J.; Abad, M.D. Sensitivity Analysis in MADM Methods: Application of Material Selection. Eng. Econ. 2016, 27, 382-391. [CrossRef]

66. Pamučar, D.; Ćirović, G. The selection of transport and handling resources in logistics centres using Multi-Attributive Border Approximation area Comparison (MABAC). Expert Syst. Appl. 2015, 42, 3016-3028. [CrossRef]

67. Han, Q.; Li, W.; Lu, Y.; Zheng, M.; Quan, W.; Song, Y. TOPSIS Method Based on Novel Entropy and Distance Measure for Linguistic Pythagorean Fuzzy Sets with Their Application in Multiple Attribute Decision Making. IEEE Access 2019, 8, 1440114412. [CrossRef]

68. Thirumalai, C.; Chandhini, S.A.; Vaishnavi, M. Analysing the concrete compressive strength using Pearson and Spearman. In Proceedings of the 2017 International conference of Electronics, Communication and Aerospace Technology (ICECA), Coimbatore, India, 20-22 April 2017; Volume 2, pp. 215-218. 